\title{
The Effect of Locally Delivered Controlled- Release Doxycycline or Scaling and Root Planing on Periodontal Maintenance Patients Over 9 Months
}

Steven Garrett, * Donald F. Adams, ${ }^{\dagger}$ Gary Bogle, ${ }^{\ddagger}$ Kevin Donly,, Connie Hastings Drisko, $\|$ William W. Hallmon, ${ }^{"}$ E. Brady Hancock,,$"$ Philip Hanes, ${ }^{* *}$ Charles E. Hawley, ${ }^{\dagger \dagger}$ Lonnie Johnson, ${ }^{\ddagger} \neq$

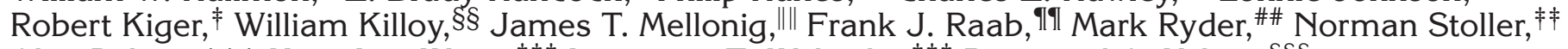
Alan Polson, ${ }^{*} * *$ Hom-Lay Wang, ${ }^{\dagger \dagger}$ Lawrence E. Wolinsky, ${ }^{, \neq} \neq$Raymond A. Yukna, $\S \S \S$ Charles Q. Harrold, ${ }^{\ddagger}{ }^{\ddagger}$ Margaret Hill,, Valerie Blanco Johnson, $§ \S$ and G. Lee Southard*

Background: This research report evaluates clinical changes resulting from local delivery of doxycycline hyclate (DH) or traditional scaling and root planing (SRP) in a group of patients undergoing supportive periodontal therapy (SPT).

Methods: In all, 141 patients received either DH (67) or SRP (74) treatment in sites $\geq 5 \mathrm{~mm}$ on one-half of their dentition at baseline and month 4.

Results: Clinical results were determined at month 9. Baseline mean probing depth recordings were similar between the two groups $(\mathrm{DH}=5.9$ $\mathrm{mm} ; \mathrm{SRP}=5.9 \mathrm{~mm}$ ). Mean month 9 results showed similar clinical results for attachment level gain (DH $0.7 \mathrm{~mm}$; SRP $0.8 \mathrm{~mm}$ ) and probing depth reduction (DH $1.3 \mathrm{~mm}$; SRP $1.1 \mathrm{~mm}$ ). Percentage of sites showing $\geq 2 \mathrm{~mm}$ attachment level gain at month 9 was $24.7 \%$ in the DH group and 21.2\% in the SRP group. Thirty-nine percent (39\%) of DH sites and 38\% of SRP sites showed $\geq 2 \mathrm{~mm}$ probing depth reduction. When treated sides of the dentition were compared to untreated sides, DH showed a difference in disease activity ( $\geq 2 \mathrm{~mm}$ attachment loss) from $19.3 \%$ (untreated) to $7.2 \%$ (treated); and SRP from 14.3\% (untreated) to $8.1 \%$ (treated).

Conclusions: Results show that both DH without concomitant mechanical instrumentation and SRP were equally effective as SPT in this patient group over the 9-month study period. J Periodontol 2000;71:22-30.

\section{KEY WORDS}

Periodontal diseases/therapy; periodontal diseases/drug therapy; planing; scaling; comparison studies; doxycycline/therapeutic use.
* Atrix Laboratories, Inc., Fort Collins, CO.

Oregon Health Sciences University, Portland, OR.

Loma Linda University, Loma Linda, CA.

$\S \quad$ University of Iowa, lowa City, IA.

University of Louisville, Louisville, KY.

I Baylor College of Dentistry, Dallas, TX.

\# Indiana University, Indianapolis, IN.

* * Medical College of Georgia, Augusta, GA.

$\dagger \dagger$ University of Maryland, Baltimore, MD.

$\neq \neq$ University of Colorado, Denver, CO.

$\S \S$ University of Missouri, Kansas City, MO.

\|| University of Texas, San Antonio, TX.

II University of Minnesota, Minneapolis, MN

\#\# University of California, San Francisco, CA.

$* * *$ University of Pennsylvania, Philadelphia, PA.

$\dagger \dagger \dagger$ University of Michigan, Ann Arbor, MI.

$\neq \ddagger$ UCLA School of Dentistry, Los Angeles, CA.

$\S \S \S$ Louisiana State University, New Orleans, LA.
$\mathrm{T}$ The goal of supportive periodontal therapy (SPT) following active periodontal treatment is to prevent recurring disease episodes and maintain the level of periodontal health achieved during the active treatment phase. Numerous studies have demonstrated and emphasized the importance of SPT in maintaining susceptible patients' periodontal health (for a review, see reference 1).

Very little data are available to determine the appropriate SPT interval for an individual periodontal patient. In the absence of specific protocols to individualize intervals, patients are usually seen every 3 to 6 months for repeat scaling and root planing. Approximately 3 of 4 patients respond well to this treatment. ${ }^{2-7}$ Therefore, while routinely delivered mechanical maintenance is effective, approximately $20 \%$ to $25 \%$ of patients have significant additional periodontal breakdown despite treatment. 
A second concern with SPT is patient compliance with proposed SPT treatments. Research reports have indicated that $34 \%$ to $42 \%$ of treated patients fail to return for their first recall appointment following active treatment. $^{8,9}$ Compliance decreases over time following treatment ${ }^{8-10}$ as well as with the complexity of treatment. ${ }^{11}$ A number of factors have been suggested that negatively affect compliance including skepticism, unfavorable treatment benefit, treatment complexity, time involved, economics, and stress. ${ }^{12}$ Unfortunately, the most effective and conscientious periodontal therapy is sometimes rendered ineffective because of patients' non-compliance with SPT.

The purpose of this study was to evaluate and compare the clinical outcomes of two separate SPT treatments in periodontal maintenance patients. The first of these treatments was scaling and root planing; the second was locally delivered controlled-release doxycycline without concomitant mechanical instrumentation.

\section{MATERIALS AND METHODS}

This group of patients represents an SPT subgroup from two previously reported randomized, blinded, multicentered trials evaluating the safety and effectiveness of locally delivered controlled-release doxycycline. Clinical outcomes following doxycycline treatment in these two parallel-design, 9-month studies were compared to scaling and root planing (SRP), oral hygiene $(\mathrm{OH})$, and vehicle control $(\mathrm{VC}){ }^{13}$ In these trials, clinical outcomes following doxycycline hyclate (DH) and SRP treatments were superior to $\mathrm{OH}$ and VC. Therefore, data from the $\mathrm{OH}$ and VC groups are not included in this report.

This SPT subgroup of patients was identified by a self-reported history of previous definitive periodontal treatment defined as scaling and root planing by quadrant and/or periodontal surgery. In addition, patients had to have undergone SPT for a minimum of 2 years post-definitive treatment, with consistent recall intervals $\leq 6$ months over that period. Specifics of the designs of the trials from which these patients were selected have been previously published. ${ }^{13,14}$

Patients were included if they gave informed consent, were 25 to 75 years of age, and had generalized moderate to severe periodontitis. To qualify, patients had at least 2 quadrants which each contained a minimum of 4 periodontal pockets $\geq 5 \mathrm{~mm}$, that bled on probing. Two of the qualifying sites were required to have a probing depth $\geq 7 \mathrm{~mm}$. Other details of the exclusion/inclusion criteria have been published previously. ${ }^{14}$

\section{DH and Treatment Procedures}

The test formulation ${ }^{\|\| \|}$containing doxycycline hyclate was a solution containing $8.5 \% \mathrm{wt} / \mathrm{wt}$ doxycycline and $37 \% \mathrm{wt} / \mathrm{wt}$ poly(DL-lactide) (PLA) dissolved in a bio- compatible carrier of $63 \% \mathrm{wt} / \mathrm{wt} \mathrm{N}$-methyl-2-pyrrolidone (NMP). In the case of DH, the two components of the formulation were provided in two separate syringes that were coupled together just prior to use and mixed for 100 cycles. Once mixed, the doxycycline-containing test product was allowed to sit at room temperature for 15 minutes and then mixed for another 10 cycles before use. A 23-gauge cannula was attached to the delivery syringe, and the test product was expressed into the periodontal pocket. Any overflow material was gently packed into the pocket with a wetted curet. Quadrants treated with $\mathrm{DH}$ were covered with a periodontal dressing. "III Patients treated with $\mathrm{DH}$ returned at day 7 for removal of the dressing and $\mathrm{DH}$ (subsequent studies have shown that removal of $\mathrm{DH}$ is unnecessary; unpublished data). DH was applied to each qualifying pocket on the treated side of the mouth at the baseline and month 4 visits. Patients in the DH treatment group were instructed not to perform oral hygiene on the treated side of the mouth during each 7-day period following treatment. No concomitant mechanical instrumentation was provided. No therapy other than $\mathrm{OH}$ was provided on the untreated side of the mouth throughout the 9-month study period.

Patients randomized to the SRP group received a single episode of SRP on the treated side of the mouth at baseline and month 4 . Therapists were instructed to continue SRP until the treated root surfaces felt hard and smooth to a dental explorer. Patients were given local anesthesia on request. No time restraints were placed on the SRP therapist; instead, treatment proceeded until the therapist was satisfied with the endpoint. SRP therapists were either periodontists or dental hygienists chosen by the principal investigator. The untreated side of the mouth did not receive any treatment other than $\mathrm{OH}$ throughout the study. Patients were instructed to begin oral hygiene on the treated side of the mouth the day following SRP.

Patients in both the DH and SRP groups received identical $\mathrm{OH}$ instructions. They were instructed in both the Bass brushing technique and proper use of dental floss to be performed 2 times a day. Compliance was queried at each subsequent visit, and further instruction was provided as necessary.

\section{Treatment Assignment and Blinding}

All patients were randomized to treatment groups according to a computer-generated random code. This was a single-blind evaluation; the examiners at each center were blinded to treatment. A double-blind design was not possible because of the dissimilar treatments between groups. 
Table I.

\section{Schematic Outline of Study Procedures}

\begin{tabular}{|c|c|c|c|c|c|c|c|c|c|}
\hline & \multicolumn{9}{|c|}{ Treatment Day } \\
\hline & Screen & Baseline & $\begin{array}{l}\text { Interim } \\
\text { Visit }\end{array}$ & $\begin{array}{c}\text { Day } \\
7\end{array}$ & $\begin{array}{l}\text { Month } \\
1,2\end{array}$ & $\begin{array}{c}\text { Month } \\
4\end{array}$ & $\begin{array}{l}\text { Interim } \\
\text { Visit }\end{array}$ & $\begin{array}{c}\text { Day } 7 \\
\text { Post-Reapplication }\end{array}$ & $\begin{array}{l}\text { Months } \\
5,6,8,9\end{array}$ \\
\hline Informed consent & $x$ & & & & & & & & \\
\hline Admission criteria & $x$ & $x$ & & & & & & & \\
\hline Pregnancy test & & $x$ & & & & $x$ & & & $x$ \\
\hline Demographics & $x$ & & & & & & & & \\
\hline Medical history & $x$ & & & & & & & & \\
\hline Blood pressure and pulse rate & $x$ & $x$ & & & & $x$ & & & \\
\hline Clinical photographs & & $x$ & $x$ & $x$ & $x$ & $x$ & $x$ & $x$ & $x$ \\
\hline Periodontal history & $x$ & & & & & & & & \\
\hline Plaque index & & $x$ & & & $x$ & $x$ & & & $x$ \\
\hline Periodontal examination & $x$ & $x$ & & & $x$ & $x$ & & & $x$ \\
\hline Administer treatments & & $x$ & & & & $x$ & & & \\
\hline Oral hygiene instruction & & $x$ & & $x$ & & $x$ & & $x$ & \\
\hline Removal of periodontal dressing & & & & $x$ & . & $x$ & & $x$ & \\
\hline Removal of test articles & & & & $x$ & & & & $x$ & \\
\hline Clinic visit & $x$ & $x$ & $x$ & $x$ & $x$ & $x$ & $x$ & $x$ & $x$ \\
\hline
\end{tabular}

\section{Evaluations}

A schedule of the evaluation timepoints and data collection at each timepoint are outlined in Table 1. Measurements of probing depth, bleeding on probing, clinical attachment level, and plaque index ${ }^{15-17}$ were made at these timepoints. Probing depth measurements were made at 6 location points on all teeth in the dentition (treated and untreated locations) using a periodontal probe, ${ }^{\# \# \# ~ g r a d u a t e d ~ i n ~} 1 \mathrm{~mm}$ increments with readings made to the nearest millimeter. Four or five sites in each of the 4 quadrants (treated and untreated) that qualified for the study ( $\geq 5 \mathrm{~mm}$ with BOP) were selected for attachment level measurements using the cementoenamel junction (CEJ) or other nearby landmark. These attachment level sites on the treated one-half of the dentition were a subset of the total sites evaluated for probing depth, bleeding score, and plaque score changes. There were continuous evaluations of both the treated and untreated sides of the dentition throughout the study, which allowed assessment of the benefits of treatment on disease progression. Concomitant medications and safety evaluations were recorded at each visit. Any suspected adverse events or allergic reactions were evaluated carefully by the investigator.
Further details concerning these evaluation appointments have been published previously. ${ }^{14}$

\section{Statistical Methods}

The patient groups from the two studies were combined for this analysis after an ANOVA for study by treatment interactions revealed no significant interactions when the DH and SRP groups from the two studies were combined. The efficacy endpoints were mean change in attachment level and probing depth. Means were calculated by using the sum of the treated and untreated site measurements for a patient divided by the number of treated and untreated sites. For all parameters, the patient mean was the basis of the statistical analysis, not the sites alone. ${ }^{18,19}$ Efficacy results for qualifying treated and untreated sites for attachment level and probing depth were analyzed statistically by analysis of variance (ANOVA) on differences from baseline values between groups. All statistical tests were conducted at a significance level of $P \leq 0.05$. All tests were two-tailed.

\section{Exclusion of Tooth Sites}

Sites on both the treated and untreated halves of the dentition were excluded from the study at the discre-

\#\#\# UNC-15, Hu-Friedy, Chicago, IL. 
tion of the principal investigator when they demonstrated $\geq 2 \mathrm{~mm}$ attachment level loss from baseline at two consecutive evaluations. Excluded sites were treated with SRP and monitored at each subsequent visit to be certain they were stable.

Procedures and criteria for study monitoring, prestudy training, data management, and exclusion of patients or investigators/centers have been described previously ${ }^{14}$ and will not be reviewed in this report.

\section{RESULTS}

The efficacy parameters evaluated were mean change in attachment level and mean change in probing depth. ANOVA analyses are presented for data combined from all centers in each study for each parameter and treatment group. The number of patients per group available for analysis varied at each analysis timepoint based on a blinded determination of whether they were efficacy-evaluable at that particular study timepoint. Patients were eliminated at various efficacy timepoints when they presented outside the predetermined evaluation timepoints or had concomitant treatment, e.g., antibiotic therapy that may have altered the results. Plaque score changes are presented as a measurement of compliance. Bleeding on probing reductions are also included. A total of 141 patients qualified for the study $-67 \mathrm{DH}$-treated patients and 74 SRP-treated patients. Sixty of the patients were female, and 81 were male. Median age was 50 years old.

\section{Plaque Scores (PS) and Bleeding on Probing (BOP)}

Baseline plaque scores were similar between treated and untreated areas of the dentition and between DH and SRP groups. Baseline PS ranged between 0.9 and 1.1. Reduction at month 9 ranged between 0.1 and 0.2 . Reductions between treated and untreated areas of the mouth and between treatments were not statistically different $(P>0.05)$. Baseline BOP ranged from 1.5 to 1.6 for both treated and untreated areas of the dentition. Reductions at month 9 ranged from 0.4 to 0.6. Reductions between treated and untreated areas were statistically significant in favor of the treated $\mathrm{DH}$ and SRP groups.

\section{Attachment Level Gain (ALG)}

Table 2 shows ALG for all evaluated sites in the treated and untreated halves of the dentition and for subgroups of moderate ( 5 to $6 \mathrm{~mm}$ ) and deep ( $\geq 7 \mathrm{~mm}$ ) sites. Results show no differences between SRP and DH groups at either 4 or 9 months. Mean month 9 ALG for all sites was $0.72 \mathrm{~mm}$ for $\mathrm{DH}$ and $0.75 \mathrm{~mm}$ for SRP; for sites initially 5 to $6 \mathrm{~mm}$, means were $0.65 \mathrm{~mm}$ for DH and $0.58 \mathrm{~mm}$ for SRP; and for sites initially $\geq 7$ $\mathrm{mm}$, these means were $0.96 \mathrm{~mm}$ for $\mathrm{DH}$ and $1.02 \mathrm{~mm}$ for SRP. Treated halves of the dentition show more improvement than untreated areas. These differences were usually significant $(P \leq 0.05)$, and mean improve- ments were somewhat larger for untreated areas in DH patients compared with untreated areas in SRP patients.

\section{Probing Depth (PD)}

Table 3 shows PD reduction for all evaluated sites in the treated and untreated halves of the dentition and for subgroups of moderate ( 5 to $6 \mathrm{~mm}$ ) and deep $(\geq 7 \mathrm{~mm})$ sites. Results show no differences between DH and SRP groups at 4 months. At month 9, DH showed statistically better PD reduction in all sites and sites 5 to $6 \mathrm{~mm}(P \leq 0.05)$. Although statistically different, these differences were not clinically relevant. Mean month 9 PD reduction for all sites was $1.28 \mathrm{~mm}$ for DH and $1.13 \mathrm{~mm}$ for SRP. DH sites with baseline PD 5 to $6 \mathrm{~mm}$ showed $1.11 \mathrm{~mm}$ reduction, and SRP showed $0.92 \mathrm{~mm}$ reduction. Sites initially $\geq 7 \mathrm{~mm}$ showed $1.76 \mathrm{~mm}$ reduction in the $\mathrm{DH}$ group and 1.67 $\mathrm{mm}$ in the SRP group. Again, treated areas of the dentition showed significantly greater improvement $(P \leq$ 0.05 ) than untreated areas, and untreated areas in DH patients showed somewhat more improvement than untreated areas in SRP patients.

\section{$A L G$ and PD Reduction $\geq 2 \mathrm{~mm}$}

Tables 4 and 5 show the number of sites and percentage of sites that experienced significant clinical change at month 9. Comparisons between DH and SRP in both Table 4 (ALG) and Table 5 (PD reduction) show similar outcomes between the groups. Approximately $30 \%$ of treated sites in both groups showed $\geq 2 \mathrm{~mm}$ ALG. Approximately $40 \%$ in both groups showed $\geq 2 \mathrm{~mm}$ PD reduction. These values are generally double those of the untreated sides of the dentition.

\section{Sites Losing $\geq 2 \mathrm{~mm}$ Attachment Level}

Table 6 compares the frequency and percentage of sites with $\geq 2 \mathrm{~mm}$ attachment level loss in DH and SRP treated groups. These values are compared to untreated halves of the dentition in the same patient groups. These data combine sites that were exited for attachment level loss $\geq 2 \mathrm{~mm}$ during the study and sites that showed this amount of loss at month 9 . The percentage of treated sites losing $\geq 2 \mathrm{~mm}$ of attachment during the study was similar between $\mathrm{DH}$ and SRP groups $(7.2 \%$ and $8.1 \%$, respectively). Treated halves of the dentition showed a substantial reduction in percentage of sites losing $\geq 2 \mathrm{~mm}$ attachment compared to untreated sides. In this intra-treatment group comparison, SRP showed a $43 \%$ reduction, and DH showed a $63 \%$ reduction.

\section{DISCUSSION}

Results of this retrospective analysis of patients undergoing supportive periodontal treatment (SPT) are consistent with the overall response seen in the large mul- 
Table 2.

Evaluation of Maintenance Patients-Attachment Level Gain (mean and SE)

\begin{tabular}{|c|c|c|c|}
\hline All Sites & Baseline & Change at Month 4 & Change at Month 9 \\
\hline \multicolumn{4}{|l|}{$\mathrm{DH}$} \\
\hline \multirow[t]{2}{*}{ Treated sites } & $6.04(0.30)$ & $0.59(0.12)$ & $0.72(0.13)$ \\
\hline & $n=67$ & $n=59$ & $n=59$ \\
\hline \multirow[t]{2}{*}{ Untreated sites } & $5.16(0.23)$ & $0.33(0.07)$ & $0.46(0.09)$ \\
\hline & $n=67$ & $n=59$ & $n=59$ \\
\hline \multicolumn{4}{|l|}{ SRP } \\
\hline \multirow[t]{2}{*}{ Treated sites } & $5.51(0.20)$ & $0.60(0.08)$ & $0.75(0.09)$ \\
\hline & $n=74$ & $n=67$ & $n=70$ \\
\hline \multirow[t]{2}{*}{ Untreated sites } & $5.34(0.24)$ & $0.30(0.08)$ & $0.34(0.08)$ \\
\hline & $n=74$ & $n=67$ & $n=70$ \\
\hline \multicolumn{2}{|l|}{ DH vs. SRP } & 0.7995 & 0.4891 \\
\hline \multicolumn{2}{|l|}{$\mathrm{DH}$ vs. untreated } & 0.0317 & 0.0354 \\
\hline \multicolumn{2}{|l|}{ SRP vs. untreated } & 0.0072 & 0.0002 \\
\hline \multicolumn{4}{|c|}{5 to $6 \mathrm{~mm}$ Baseline Probing Depth } \\
\hline \multicolumn{4}{|c|}{$\mathrm{DH}^{*}$} \\
\hline \multirow[t]{2}{*}{ Treated sites } & $5.23(0.27)$ & $0.54(0.10)$ & $0.65(0.11)$ \\
\hline & $n=65$ & $n=57$ & $n=56$ \\
\hline \multirow[t]{2}{*}{ Untreated sites } & $4.88(0.25)$ & $0.23(0.07)$ & $0.44(0.09)$ \\
\hline & $n=65$ & $n=57$ & $n=56$ \\
\hline \multicolumn{4}{|l|}{ SRP } \\
\hline \multirow[t]{2}{*}{ Treated sites } & $4.87(0.20)$ & $0.44(0.08)$ & $0.58(0.09)$ \\
\hline & $n=74$ & $n=67$ & $n=70$ \\
\hline \multirow[t]{2}{*}{ Untreated sites } & $5.07(0.23)$ & $0.29(0.08)$ & $0.34(0.09)$ \\
\hline & $n=74$ & $n=67$ & $n=70$ \\
\hline \multicolumn{2}{|l|}{ DH vs. SRP } & 0.7230 & 0.2830 \\
\hline \multicolumn{2}{|l|}{ DH vs. untreated } & 0.0085 & 0.1018 \\
\hline \multicolumn{2}{|l|}{ SRP vs. untreated } & 0.1587 & 0.0228 \\
\hline \multicolumn{4}{|c|}{$\geq 7 \mathrm{~mm}$ Baseline Probing Depth } \\
\hline \multicolumn{4}{|c|}{$\mathrm{DH}^{* * *}$} \\
\hline \multirow[t]{2}{*}{ Treated sites } & $7.32(0.35)$ & $0.65(0.16)$ & $0.96(0.17)$ \\
\hline & $n=64$ & $n=55$ & $n=55$ \\
\hline \multirow[t]{2}{*}{ Untreated sites } & $6.47(0.28)$ & $0.61(0.18)$ & $0.57(0.18)$ \\
\hline & $n=47$ & $n=41$ & $n=42$ \\
\hline \multicolumn{4}{|l|}{ SRP } \\
\hline \multirow[t]{2}{*}{ Treated sites } & $6.94(0.29)$ & $0.82(0.13)$ & $1.02(0.14)$ \\
\hline & $n=71$ & $n=66$ & $n=66$ \\
\hline \multirow[t]{2}{*}{ Untreated sites } & $6.83(0.39)$ & $0.34(0.16)$ & $0.54(0.16)$ \\
\hline & $n=45$ & $n=42$ & $n=42$ \\
\hline DH vs. SRP & & 0.2160 & 0.6022 \\
\hline DH vs. untreated & & 0.7718 & 0.1406 \\
\hline SRP vs. untreated & & 0.0013 & 0.0205 \\
\hline
\end{tabular}

* Two patients in the DH group did not have AL sites with pockets measuring 5 to $6 \mathrm{~mm}$ at baseline.

** Three patients in the DH group did not have AL sites with pockets measuring $\geq 7 \mathrm{~mm}$ at baseline. 
Table 3.

\section{Evaluation of Maintenance Patients-Probing Depth Reduction (mean and SE)}

\begin{tabular}{|c|c|c|c|}
\hline All Sites & Baseline & Change at Month 4 & Change at Month 9 \\
\hline \multicolumn{4}{|l|}{$\mathrm{DH}$} \\
\hline \multirow[t]{2}{*}{ Treated sites } & $5.93(0.05)$ & $-0.98(0.09)$ & $-1.28(0.09)$ \\
\hline & $n=67$ & $n=59$ & $n=59$ \\
\hline \multirow[t]{2}{*}{ Untreated sites } & $5.68(0.07)$ & $-0.46(0.07)$ & $-0.66(0.09)$ \\
\hline & $n=64$ & $n=59$ & $n=59$ \\
\hline \multicolumn{4}{|l|}{ SRP } \\
\hline \multirow[t]{2}{*}{ Treated sites } & $5.86(0.05)$ & $-1.00(0.09)$ & $-1.13(0.09)$ \\
\hline & $n=74$ & $n=67$ & $n=70$ \\
\hline \multirow[t]{2}{*}{ Untreated sites } & $5.58(0.05)$ & $-0.55(0.06)$ & $-0.55(0.07)$ \\
\hline & $n=74$ & $n=67$ & $n=70$ \\
\hline DH vs. SRP & & 0.6306 & 0.0294 \\
\hline DH vs. untreated & & 0.0001 & 0.0001 \\
\hline SRP vs. untreated & & 0.0001 & 0.0001 \\
\hline \multicolumn{4}{|c|}{5 to $6 \mathrm{~mm}$ Baseline Probing Depth } \\
\hline \multicolumn{4}{|l|}{$\mathrm{DH}$} \\
\hline \multirow[t]{2}{*}{ Treated sites } & $5.36(0.02)$ & $-0.86(0.08)$ & $-1.11(0.08)$ \\
\hline & $n=67$ & $n=59$ & $n=59$ \\
\hline \multirow[t]{2}{*}{ Untreated sites } & $5.28(0.03)$ & $-0.37(0.07)$ & $-0.57(0.09)$ \\
\hline & $n=67$ & $n=59$ & $n=59$ \\
\hline \multicolumn{4}{|l|}{ SRP } \\
\hline \multirow[t]{2}{*}{ Treated sites } & $5.33(0.02)$ & $-0.83(0.07)$ & $-0.92(0.08)$ \\
\hline & $n=74$ & $n=67$ & $n=70$ \\
\hline \multirow[t]{2}{*}{ Untreated sites } & $5.26(0.02)$ & $-0.53(0.07)$ & $-0.52(0.07)$ \\
\hline & $n=74$ & $n=67$ & $n=70$ \\
\hline \multicolumn{2}{|l|}{ DH vs. SRP } & 0.4268 & 0.0302 \\
\hline \multicolumn{2}{|l|}{ DH vs. untreated } & 0.0001 & 0.0001 \\
\hline \multicolumn{2}{|l|}{ SRP vs. untreated } & 0.0018 & 0.0001 \\
\hline \multicolumn{4}{|c|}{$\geq 7 \mathrm{~mm}$ Baseline Probing Depth } \\
\hline \multicolumn{4}{|l|}{$\mathrm{DH}$} \\
\hline \multirow[t]{2}{*}{ Treated sites } & $7.54(0.07)$ & $-1.22(0.14)$ & $-1.76(0.14)$ \\
\hline & $n=67$ & $n=58$ & $n=58$ \\
\hline \multirow[t]{2}{*}{ Untreated sites } & $7.44(0.09)$ & $-0.78(0.14)$ & $-1.02(0.17)$ \\
\hline & $n=50$ & $n=44$ & $n=44$ \\
\hline \multicolumn{4}{|l|}{ SRP } \\
\hline \multirow[t]{2}{*}{ Treated sites } & $7.56(0.09)$ & $-|.5|(0.15)$ & $-1.67(0.15)$ \\
\hline & $n=74$ & $n=66$ & $n=68$ \\
\hline \multirow[t]{2}{*}{ Untreated sites } & $7.44(0.08)$ & $-0.77(0.10)$ & $-0.90(0.13)$ \\
\hline & $n=48$ & $n=45$ & $n=45$ \\
\hline \multicolumn{2}{|l|}{ DH vs. SRP } & 0.7429 & 0.1574 \\
\hline \multicolumn{2}{|l|}{ DH vs. untreated } & 0.0266 & 0.0008 \\
\hline \multicolumn{2}{|l|}{ SRP vs. untreated } & 0.0001 & 0.0001 \\
\hline
\end{tabular}


Table 4.

\section{Evaluation of Maintenance Patients- Attachment Level Change $\geq 2 \mathrm{~mm}$}

\begin{tabular}{lcccc}
\hline & \multicolumn{2}{c}{ Treated Sites } & \multicolumn{2}{c}{ Untreated Sites } \\
& $\mathrm{N}$ & $\%$ & $\mathrm{~N}$ & $\%$ \\
\hline$\geq 2 \mathrm{~mm}$ improvement & & & & \\
DH & 157 & 31.2 & 107 & 24.7 \\
SRP & 177 & 29.4 & 110 & 21.2 \\
$\geq 2 \mathrm{~mm}$ loss & & & & \\
DH & 29 & 5.8 & 29 & 6.7 \\
SRP & 27 & 4.5 & 40 & 7.7 \\
Total sites & & & & \\
DH & 504 & & 434 & \\
SRP & 603 & & 518 & \\
\hline
\end{tabular}

Table 5.

\section{Evaluation of Maintenance Patients- Probing Depth Change $\geq 2 \mathrm{~mm}$}

\begin{tabular}{lcccc}
\hline & Treated Sites & \multicolumn{2}{c}{ Untreated Sites } \\
& $N$ & $\%$ & $N$ & $\%$ \\
\hline Reduction 2 mm & & & & \\
DH & 405 & 39.2 & 150 & 19.6 \\
SRP & 460 & 37.5 & 177 & 19.9 \\
Gain 2 mm & & & & \\
DH & 7 & 0.7 & 16 & 2.1 \\
SRP & 14 & 1.1 & 16 & 1.8 \\
Total sites & & & & \\
DH & 1032 & & 765 & \\
SRP & 1228 & & 891 & \\
\hline
\end{tabular}

ticenter trials from which this patient subset was derived. In these two multicenter trials, outcomes between DH and SRP groups were clinically equivalent ${ }^{13}$ as they were in this analysis. There were no clinical and only minor statistical differences in ALG, PD reduction, and BOP reduction when SPT was accomplished by DH treatment without concomitant instrumentation or by traditional SRP.

Of particular importance was the impact of each of these therapies on the rate of disease progression in the patient's dentition. The study design allowed intra-
Table 6.

\section{Sites Losing $\geq 2 \mathrm{~mm}$ Attachment Level}

\begin{tabular}{lccc}
\hline & Total Sites & Losing Sites* & $\%$ \\
\hline $\mathrm{DH}$ & 512 & 37 & 7.2 \\
Treated & 502 & 97 & 19.3 \\
Untreated & & \\
SRP & 627 & 51 & 8.1 \\
Treated & 558 & 80 & 14.3 \\
Untreated & &
\end{tabular}

patient comparisons of disease activity in monitored sites on treated and untreated halves of the dentition over the 9-month study period. Disease progression was defined as sites that showed a loss of attachment level $\geq 2 \mathrm{~mm}$ over the 9 -month study period. There was an approximate $63 \%$ difference in activity comparing treated and untreated areas of the dentition following $\mathrm{DH}$, and a 43\% difference following SRP treatment. In this patient population, overall disease activity was higher than expected. ${ }^{20-22}$ This may relate to the population being evaluated. These were patients who had received definitive periodontal care and had been compliant with SPT visits ( $\leq 6$-month intervals) for at least 2 years. Despite this, they qualified to enter the study by having at least 2 quadrants that each had 4 or more sites $\geq 5 \mathrm{~mm}$ that bled on probing. Two of these sites had to be $\geq 7 \mathrm{~mm}$. This likely represents an increased disease activity compared to a general SPT population. ${ }^{20-22}$ Additionally, the rate of disease activity in both the treated and untreated halves of the dentition may have been influenced by not treating the entire dentition. Several recent research reports indicate that full-mouth treatment, rather than a quadrant or split-mouth approach, results in a more positive clinical response overall which may be due to the decreased overall bacterial load. ${ }^{23,24}$ These data are strong evidence of the benefit of frequent SPT in similar patient populations.

Research indicates that tetracyclines may be used in conjunction with SRP in SPT patients ${ }^{25,26}$ or as a monotherapy in refractory SPT patients ${ }^{27}$ with considerable success. These data indicate that DH may have potential use as an alternate treatment to SRP at SPT visits where root planing is not required. These DH treatments, used periodically when clinical conditions indicate, may improve the generally poor visit compliance seen in SPT patients. ${ }^{8-11}$ Lack of visit compliance negatively affects outcomes following definitive periodontal treatment. ${ }^{22,28,29}$ It is unknown whether 
use of treatment alternatives to routine root planing will improve visit compliance in SPT patients. Additional studies are necessary to demonstrate any improvements in compliance.

Treatment with DH seemed to result in a modest crossover effect to untreated halves of the dentition, despite the somewhat higher incidence of sites losing $\geq 2 \mathrm{~mm}$ of attachment level in the DH group. Generally, mean improvement in ALG and PD reduction was slightly greater in untreated areas of $\mathrm{DH}$ patients compared with SRP patients. This may be a result of crossover of DH from treated to untreated areas of the dentition. A recent pharmacokinetic study has shown modest levels of doxycycline in the saliva following DH treatment of half the dentition. ${ }^{30}$ This reinforces the importance of a parallel rather than split-mouth design when evaluating similar products.

One drawback of the study is its 9-month design with repeat treatment at month 4 . This provides no information regarding whether $\mathrm{DH}$ treatment may prolong the SPT interval as has been suggested following use of tetracycline-impregnated fibers. ${ }^{26}$ In addition, 9-month data with only two treatments provide little information regarding long-term effects of DH treatment. One recent report has shown little long-term benefit following use of tetracycline fibers. ${ }^{31}$ However, this report contained relatively few patients and, as the authors suggested, the data may have been skewed by patients in the fiber group that showed unusually high rates of disease activity. This illustrates the necessity of properly powered evaluations to assess outcomes. Other reports have demonstrated long-term stability following tetracycline fiber application. ${ }^{32}$ Finally, stability of outcomes following any type of periodontal therapy is SPT dependent. $^{1,7}$ It is assumed that DH-treated patients in routine clinical practice will eventually require root planing as a part of ongoing SPT. Therefore, significantly longerterm results that do not include root planing as part of SPT may not be available.

In conclusion, this study demonstrates that SPT using $\mathrm{DH}$ (without concomitant mechanical treatment) is as effective as SRP in reducing the clinical signs of periodontitis over 9 months. This suggests that DH treatment may be an effective SPT treatment in patients who do not require root planing at their SPT visit. Additional studies are necessary to demonstrate the feasibility of this treatment routine and whether it will improve SPT compliance. Both DH and SRP demonstrated positive effects on the rate of disease progression compared with untreated areas in patients' dentition. This emphasizes the importance of frequent SPT visits and compliance with these visits in maintaining periodontal health.

\section{ACKNOWLEDGMENTS}

Dr. Southard is president and chief scientific officer of Atrix Laboratories, Inc. Dr. Garrett is vice president for clinical research at Atrix Laboratories, Inc. This study was supported by Atrix Laboratories, Inc. The authors would like to thank Michelle Pennock for manuscript preparation and Graham Carron and Barbara Pons for data management and statistical considerations.

\section{REFERENCES}

1. McFall WT. Supportive treatment. In: Nevins M, Becker W, Kornman K, eds. Proceedings of the World Workshop in Clinical Periodontics. Chicago: American Academy of Periodontology; 1989:IX1-IX23.

2. Hirschfield I, Wasserman B. A long-term survey of tooth loss in 600 treated periodontal patients. J Periodontol 1978;49:225-237.

3. Ross IF, Thompson RH. A long-term study of root retention in the treatment of maxillary molars with furcation involvement. J Periodontol 1978;49:238-244.

4. McFall WT. Tooth loss in 100 treated patients with periodontal disease: A long-term study. J Periodontol 1982; 53:539-549.

5. Goldman MJ, Ross IF, Goteiner D. Effect of periodontal therapy on patients maintained for 15 years or longer. A retrospective study. J Periodontol 1986;57:347-353.

6. Nabers CI, Stalker WH, Esparza D, Naylor B, Canales S. Tooth loss in 1,535 treated periodontal patients. J Periodontol 1988;59:297-300.

7. Baehni PC, Tessler JF. Supportive periodontal care. In: Lang NP, Karring T, eds. Proceeding of the First European Workshop on Periodontology. London: Quintessence Publishing Co. Ltd.; 1994:274-288.

8. Wilson TG, Glover ME, Schoen J, et al. Compliance with maintenance therapy in a private periodontal practice. $J$ Periodontol 1984;55:468-473.

9. Galgut PN. Compliance with maintenance therapy after periodontal treatment. Dent Health (London) 1991;30 (6):3-7.

10. Mendoza AR, Newcomb GM, Nixon KC. Compliance with supportive periodontal therapy. J Periodontol 1991; 62:731-736.

11. Checchi L, Pelliccioni GA, Gatto MR, Kelescian L. Patient compliance with maintenance therapy in an Italian periodontal practice. J Clin Periodontol 1994;21:309-312.

12. Wilson TG, Glover ME, Malik AK, et al. Tooth loss in maintenance patients in a private periodontal practice. $J$ Periodontol 1987;58:231-235.

13. Garrett S, Johnson L, Drisko CH, et al. Two multicenter studies evaluating locally delivered doxycycline hyclate, placebo control, oral hygiene and scaling and root planing in the treatment of periodontitis. J Periodontol 1999;70:490-503.

14. Polson AM, Garrett S, Stoller NH, et al. Multicenter comparative evaluation of subgingivally delivered sanguinarine and doxycycline in the treatment of periodontitis. I. Study design, procedures, and management. J Periodontol 1997;68:110-118.

15. Ramfjord SP. The periodontal index (PDI). J Periodontol 1967;38:602-610.

16. Polson AM, Southard GL, Dunn RL, et al. Initial study of guided tissue regeneration in Class II furcation defects after use of a biodegradable barrier. Int $J$ Periodontics Restorative Dent 1995;15:43-55.

17. Silness J, Löe H. Periodontal disease in pregnancy. II. Correlation between oral hygiene and periodontal condition. Acta Odontol Scand 1964;22:121-135.

18. Laster L. The effect of subsampling sites within patients. $J$ Periodont Res 1985;20:91-96. 
19. Goodson JM, Cugini MA, Kent RL, et al. Multicenter evaluation of tetracycline fiber therapy. II. Clinical response. J Periodont Res 1991;26:371-379.

20. Knowles JW, Burgett FG, Nissle RR, et al. Results of periodontal treatment related to pocket depth and attachment level. Eight years. J Periodontol 1979;50:225-233.

21. Badersten A, Nilveus R, Egelberg J. Four-year observations of basic periodontal therapy. $J$ Clin Periodontol 1987; $14: 438-444$.

22. Axelsson $\mathrm{P}$, Lindhe $\mathrm{J}$. The significance of maintenance in the treatment of periodontal disease. J Clin Periodontol 1981;8:281-288.

23. Quirynen M, Bollen CML, Vandekerckhove BNA, et al. Full versus partial-mouth disinfection in the treatment of periodontal infections. Short-term clinical and microbiological observations. J Dent Res 1995;74:1459-1467.

24. Bollen CML, Mongardini C, Papaioannou W, et al. The effect of a one-stage full-mouth disinfection on different intra-oral niches. Clinical and microbiological observations. J Clin Periodontol 1998;25:56-66.

25. Newman M, Kornman KS, Doherty F. A 6-month multicenter evaluation of adjunctive tetracycline fiber therapy used in conjunction with scaling and root planing in maintenance patients. J Periodontol 1994;65:685691.

26. Michalowicz BS, Pihlstrom BL, Drisko CL, et al. Evaluation of periodontal treatments using controlled-release tetracycline fibers: Maintenance response. J Periodontol 1995;66:708-715.

27. Vandekerckhove BNA, Quirynen M, van Steenberghe D. The use of tetracycline-containing controlled-release fibers in the treatment of refractory periodontitis. J Periodontol 1997;68:353-361.

28. Becker W, Becker BE, Berg LE. Periodontal treatment without maintenance. A retrospective study in 44 patients. J Periodontol 1984;55:505-509.

29. Wilson TG, Glover ME, Malik AK, et al. Tooth loss in maintenance patients in private periodontal practice. $J$ Periodontol 1987;58:231-235.
30. Stoller NH, Johnson LR, Trapnell S, et al. The pharmacokinetic profile of a biodegradable controlled-release delivery system containing doxycycline compared to systemically delivered doxycycline in gingival crevicular fluid, saliva, and serum. J Periodontol 1998;69:10851091.

31. Wilson TG, McGuire MK, Greenstein G, Nunn M. Tetracycline fiber plus scaling and root planing versus scaling and root planing alone: Similar results after 5 years. J Periodontol 1997;68:1029-1032.

32. Goodson JM, Oppenheim R, Hanson D, Doucette D. Statistical analysis of tetracycline fiber therapy from an SQL database model for periodontal disease monitoring. J Dent Res 1998;77(Spec. Issue):923(Abstr. 2335).

Send reprint requests to: Dr. Steven Garrett, Atrix Laboratories, Inc., 2579 Midpoint Dr., Fort Collins, CO 80525-4417. Fax: 970/482-9735.

Accepted for publication May 7, 1999. 